(Mus. Comp. Zool., Harvard Univ., 133, No. 6: The Fossil Elephant Shrews; 1966). He supplies a diagnosis and achieves a neat rehousing of some African Tertiary mammals which had previously been misplaced among marsupials, mixtodectid insectivores and hyracoids. The order has only one family, the Macroscelididae; it is entirely African, and ranges from Lower Oligocene to Recent. The extinct sub-families were essentially herbivorous while the living members are more markedly omnivorous.

Reed and Turnbull have described the insectivore genera Arctoryctes and Cryptoryctes from the Oligocene and Miocene of North America (Fieldiana: Geol., 15, No. $2 ; 1966)$. They provide a detailed account of the functional anatomy of the bones of the forelimb and shoulder girdle of the fossil forms, and compare them with living talpid moles. The trends in the two groups are broadly parallel but differ in detail; the arctryctines are more specialized while the talpids have the lead in overall efficiency of the limb.

\section{Domestic into General Science}

Quenn Elizabeth College of the University of London is taking another important step in the transition from its original role as King's College of Household and Social Science to a general science college. After 20 years as principal, Miss M. J. Sargeaunt is retiring in September and Dr. Kenneth G. Denbigh, professor of chemical engineering at Imperial College, London, since 1961, will be the new principal. Although he has not made formal plans, Prof. Denbigh hopes the college will keep growing as a scientific centre. Because space is limited he thinks the college will never be large and that growth will be directed more towards quality than quantity.

The college was founded in 1908 as a branch of King's College for Women and in 1928 became a separate school of the University as the College of Household and Social Science. In 1953 it was granted a royal charter under the title Queen Elizabeth College, but continued to give only courses in household science and nutrition until 1957. Since these courses involved the basic sciences and there were already active departments of physics, chemistry, biology, microbiology, and physiology, it was a simple step to introduce a B.Sc. (General) degree and a department of mathematics in 1957; special degree courses in microbiology and mathematics soon followed, with chemistry and physics courses planned for 1966. This change has proved so successful over the past ten years that of the 423 students enrolled last year, only 121 were studying household science or nutrition, while 223 were enrolled for the special or general science degrees.

The physical growth of the college has kept pace, as far as possible, with the scholastic expansion. The Sir John Atkins Laboratories, containing enlarged departments of biology, microbiology and nutrition and an isotope unit, were completed in 1960. By 1968 an extension to these laboratories should be completed, together with new buildings for the departments of chemistry and mathematics and more room for students. With the completion of a planned third stage, an extension of the physics and physiology departments, the college will be able to double or more its present number of students. Miss Sargeaunt has left Prof. Denbigh a sound foundation upon which to build.

\section{Lister Institute-1966}

THE London Lister Institute of Preventive Medicine has had another good year, as judged from the annual report for 1966. Although it gets no money from the University Grants Committee, the Institute is one of the recognized schools of the University of London for postgraduate research, and during 1965-66 there were sixteen postgraduate research workers at the Institute registered for higher degrees. Also embodied within the Lister are three units of the Medical Research Council-the Trachoma Research Unit, the Blood Group Rescarch Unit and the Blood Group Reference Laboratory.

The research bcing undertaken involves the genetics, physiology and morphology of bacteria, trypanosomiasis, various aspects of virus diseases and bacterial infections, immunology, human blood group substances, biochemistry of lipids, macro-molecular components of blood, and human plasma proteins. In recent years, increasing emphasis has been placed on various aspects of virology and immunology. In virology, there have been considerable developments in studies of trachoma agents, and of special importance has been the success in passaging trachoma and inclusion conjunctivitis agents in the lungs of mice. The possibilities are being investigated of producing a potent vaccine free from those substances in nervous tissue which are responsible for the demyelinating accidents which sometimes occur during the treatment of rabies. New fields of research in immunology include investigations to test the possibility that generalized eczema may result from the incorporation of bacterial or fungal antigens into cells of the skin. There is also an investition of the possibility that nodular vasculitis may be caused by complexes of antigen and antibody.

\section{Outlook for Locusts}

DESERT locust plagues, from Algeria to India, may soon be terrors of the past. The third annual report of the Desert Locust Control Organization for Eastern Africa-established by the governments of Ethiopia, France, Kenya, Somali Republic, Tanzania and Uganda (see Nature, 20\%, p. 21)-states that, for the first time since 1939, two years have gone by since the desert 'ocust has been a cause of concern. It concludes that "the existing recession could be extended indefinitely with adequate vigilance and efficient planning",.

During 1964-1965, the Republic of Sudan was invited to become a member of the Organization, and the Federation of South Arabia, although outside the region, was made a working partner by means of a formal agreement negotiated by the Food and Agriculture Organization of the United Nations. To increase its scope and impact still further, the Organization was brought within the framework of the FAO. The United States Agency for International Development also transferred to the Organization its locust control programme in East Africa.

This expansion of activities and consolidation of concerned agencies is necessary, for the problems to be solved involve large areas and demand constant surveillance. Desert locusts affect an area of approximately 25 million square kilometres, live from three weeks to three months, and may multiply 10 to 20 times in number each generation. 